\title{
Profile of saxagliptin in the treatment of type 2 diabetes: focus on Japanese patients
}

This article was published in the following Dove Press journal:

Therapeutics and Clinical Risk Management

II July 2014

Number of times this article has been viewed

\author{
Hiroyuki Konya' \\ Yuzo Yano' \\ Satoshi Matsutani' \\ Taku Tsunoda ${ }^{2}$ \\ Takashi Ikawa ${ }^{2}$ \\ Yoshiki Kusunoki \\ Toshihiro Matsuo ${ }^{2}$ \\ Masayuki Miuchi² \\ Tomoyuki Katsuno ${ }^{3}$ \\ Tomoya Hamaguchi ${ }^{4}$ \\ Jun-ichiro Miyagawa ${ }^{2}$ \\ Mitsuyoshi $\mathrm{Namba}^{2}$ \\ 'Department of Internal Medicine, \\ Ashiya Municipal Hospital, Ashiya, \\ ${ }^{2}$ Division of Diabetes, Endocrinology \\ and Metabolism, Department of \\ Internal Medicine, ${ }^{3}$ Division of \\ Innovative Diabetes Treatment, Hyogo \\ College of Medicine, Nishinomiya, \\ ${ }^{4}$ Division of Diabetes, Department of \\ Internal Medicine, Itami City Hospital, \\ Itami, Hyogo, Japan
}

Correspondence: Hiroyuki Konya Department of Internal Medicine, Ashiya Municipal Hospital, 39-I Asahigaoka-cho, Ashiya, Hyogo 659-8502, Japan

Tel +81797312156

Fax +8179722 8822

Email h-dyer@mvi.biglobe.ne.jp
Abstract: Saxagliptin is a selective and potent dipeptidyl peptidase (DPP)-4 inhibitor, approved as an adjunct to diet and exercise to improve glycemic control in type 2 diabetes mellitus (T2DM) in the USA on July 2009, and had been launched globally in over 86 countries by September 2013. In patients with T2DM, once-daily administration of saxagliptin before breakfast achieves sustained inhibition of plasma DPP-4 activity and reduction of postprandial hyperglycemia, including after dinner, associated with an increase in plasma glucagon-like peptide-1 levels. This paper reviews the safety and efficacy of saxagliptin in Japanese patients with T2DM. The clinical development study in Japan supported its usefulness for the disease. Saxagliptin 1, 2.5, and $5 \mathrm{mg}$ led to significant improvements in glycated hemoglobin $\left(\mathrm{HbA}_{1 \mathrm{c}}\right)$, and was generally well tolerated. Treatment with saxagliptin $5 \mathrm{mg}$ induced a sustained reduction in $\mathrm{HbA}_{1 \mathrm{c}}$ over 52 weeks. Long-term combination therapy with saxagliptin and other oral hypoglycemic agents also provided sustained glycemic control and was well tolerated for up to 52 weeks. Saxagliptin as add-on to sulfonylureas or glinides has a tendency to increase hypoglycemia, but not with other oral antidiabetic agents, such as $\alpha$-glucosidase inhibitors, metformin, or thiazolidinediones. The results of clinical trials have confirmed the long-term efficacy and safety of saxagliptin monotherapy as well as its use as add-on combination therapy, and support its usefulness as a therapeutic agent for T2DM. Saxagliptin has less concern for hypoglycemia and weight gain, which often becomes problematic in routine care of T2DM. Meta-analysis of clinical trials in the USA showed no evidence of increased risk of cardiovascular events associated with saxagliptin, suggesting the superior of saxagliptin in terms of safety. Recently, investigators in the SAVOR-TIMI (Saxagliptin Assessment of Vascular Outcomes Recorded in Patients with Diabetes Mellitus-Thrombolysis in Myocardial Infarction) 53 study suggested that DPP-4 inhibition with saxagliptin did not increase or decrease the rate of ischemic events, although the rate of hospitalization for heart failure was increased. Although saxagliptin improves glycemic control, other approaches are necessary to reduce cardiovascular risk in patients with diabetes. Saxagliptin is applicable for various pathological conditions, and is considered to be clinically significant as a new therapeutic option for Japanese patients with T2DM.

Keywords: dipeptidyl peptidase-4, incretin hormones, saxagliptin, type 2 diabetes mellitus, Japan, efficacy, safety, patient acceptability

\section{Introduction}

Diabetes mellitus is a complex metabolic disorder and one of the main chronic diseases worldwide. The number of people with diabetes mellitus globally was estimated at 382 million in 2013, and is expected to reach over 592 million by $2035 .{ }^{1}$ Close to 5.1 million deaths in adults aged 20-79 years were attributable to diabetes mellitus in 2013 , accounting for $8.4 \%$ of the global all-cause mortality in this age group. ${ }^{2}$ A number

submit your manuscript $\mid$ www.dovepress.con 
of antidiabetic drugs can be used, including sulfonylureas, metformin, $\alpha$-glycosidase inhibitors, thiazolidinediones (TZDs), glinides, and insulin.

Recently, a new therapeutic approach for the treatment of type 2 diabetes mellitus (T2DM) that targets the incretin hormones has been developed. These peptide hormones, ie, glucagon-like peptide 1 (GLP-1) and glucose-dependent insulinotropic peptide, are released from the intestine after a meal and stimulate insulin secretion in a glucose-dependent fashion. ${ }^{3}$ However, their action is limited by rapid inactivation via the enzyme dipeptidyl peptidase (DPP)-4. In addition, patients with T2DM usually do not respond well to glucosedependent insulinotropic peptide and GLP-1. ${ }^{4,5}$ Inhibition of DPP-4 will increase levels of active incretins, so DPP-4 has become a target in diabetes control. ${ }^{6-8}$

Incretin-based therapy was first made available for the treatment of T2DM in the USA in 2006 and in Japan in 2009. ${ }^{9}$ To date, seven DPP-4 inhibitors are available in Japan, including sitagliptin, vildagliptin, alogliptin, linagliptin, anagliptin, teneligliptin, and saxagliptin..$^{9-12}$ The effects of incretin-based therapy have been assumed to be exerted mainly through the hormonal and neuronal actions of one of the incretins, GLP-1, which is secreted from L cells localized in the small intestine. The benefits of this therapy over conventional sulfonylureas or insulin injections, such as fewer hypoglycemic events and less body weight gain, derive from the glucose-dependent insulinotropic effect. The protective effects of this therapy on vulnerable pancreatic $\beta$-cells and against micro/macroangiopathy in T2DM are also most welcome. Indications and/or contraindications for incretin-based therapy should be clarified by prospectively studying the experiences of Japanese patients with T2DM undergoing this therapy in the clinical setting. ${ }^{9}$ DPP4 inhibitors, pharmacokinetics/pharmacodynamics, efficacy, safety, and tolerability have been assessed in numerous clinical studies. ${ }^{13}$

Saxagliptin is a potent, selective DPP-4 inhibitor approved as an adjunct to diet and exercise to improve glycemic control in adults with T2DM. ${ }^{14}$ As monotherapy, saxagliptin $2.5,5$, and $10 \mathrm{mg}$ led to statistically significant improvements in glycemic indices versus placebo at week 24, and was generally well tolerated in treatment-naïve patients with T2DM. Hypoglycemic events were comparable between saxagliptin treatment groups and placebo, and there were no increases in weight. ${ }^{15}$ Long-term efficacy and safety data for saxagliptin as add-on therapy to metformin, ${ }^{16}$ sulfonylureas, ${ }^{17}$ or TZDs, ${ }^{18}$ or as initial combination therapy with metformin ${ }^{19}$ have been published, and long-term data (76 weeks) have been published for saxagliptin monotherapy at the approved doses of 2.5 and $5 \mathrm{mg}^{20}$

Poolsup et al reported a meta-analysis of the efficacy of various antidiabetic agents as add-on treatments to metformin. Eight studies were identified in their paper. TZDs were as effective as DPP-4 inhibitors in reducing glycated hemoglobin $\left(\mathrm{HbA}_{1 \mathrm{c}}\right)$. Compared with sulfonylureas, TZDs reduced fasting plasma insulin more effectively than sulfonylureas, but no significant differences were detected with regard to the effects on $\mathrm{HbA}_{1 \mathrm{c}}$ and fasting plasma glucose. It was shown that TZDs reduced fasting plasma glucose better than did DPP-4 inhibitors and decreased fasting plasma insulin more than did sulfonylureas. ${ }^{21}$ Gross et al also reported a meta-analysis of the efficacy of various antidiabetic agents as add-on treatments to metformin and sulfonylureas. Eighteen trials involving 4,535 participants and with a mean duration of 31.3 (range 24-52) weeks were included. Compared with placebo, the drug classes did not differ in their effect on $\mathrm{HbA}_{1 \mathrm{c}}$. Weight increase was seen with insulins and TZDs, and weight loss was seen with GLP-1 agonists. Insulins were associated with twice the absolute number of severe hypoglycemic episodes when compared with noninsulin antihyperglycemic agents. ${ }^{22}$ Recently, Phung et al reported on early combination therapy as add-on to metformin. Fifteen trials involving 6,693 participants and a mean treatment duration of 6 months were included. Drugs combined with metformin included TZDs, insulin secretagogues, DPP-4 inhibitors, and sodium glucose transporterase inhibitors. Compared with metformin alone, combination therapy with metformin achieved statistically significant reductions in $\mathrm{HbA}_{1 \mathrm{c}}$, an increase in the number of patients achieving their $\mathrm{HbA}_{1 \mathrm{c}}$ goal of $<7 \%$, and reductions in fasting plasma glucose. It was suggested that there was a potential benefit of initial combination therapy on glycemic outcomes in diabetes when compared with metformin monotherapy across a wide range of baseline $\mathrm{HbA}_{1 \mathrm{c}}$ levels. ${ }^{23}$ This paper discusses the efficacy, safety, and acceptability of saxagliptin in treating Japanese patients with T2DM.

\section{Characteristics of Japanese patients with T2DM}

T2DM results from a deterioration of both insulin secretion and insulin action, ${ }^{24}$ but the contribution of these factors to glucose intolerance varies between different ethnic groups. In Japanese, reduced insulin-secreting capacity is considered to play a more important role than impaired insulin resistance during the transition from normal glucose tolerance to impaired glucose tolerance, and then to 
overt T2DM. ${ }^{25}$ The insulinogenic index is calculated by dividing the increment in serum insulin from 0 to 30 minutes during an oral glucose tolerance test by the increment in plasma glucose during the same period. The insulinogenic index is a marker of early-phase insulin-secretion capacity in response to a rise in blood glucose levels. ${ }^{26} \mathrm{~A}$ low insulinogenic index has been described in Japanese patients, independent of glucose tolerance status, when compared with Caucasian patients. ${ }^{27}$ The low insulinogenic index in Japanese patients is thought to reflect $\beta$-cell fragility. Fukuda-Akita et al reported a positive association between body mass index (BMI) and insulinogenic index in diabetic patients, and that BMI was an independent determinant of the insulinogenic index. ${ }^{28}$ Given that mean BMI is much lower in the Japanese than in Caucasians, ${ }^{29}$ it is possible that the early-phase decrease in insulin secretion in Japanese diabetic patients is partly a result of their lower BMI. On the one hand, Matsumoto et al showed that the insulinogenic index is decreased in both nonobese and obese subjects with impaired glucose tolerance or T2DM. ${ }^{25}$ On the other hand, Iwahashi et al reported that insulinogenic index values among both those with impaired glucose tolerance and T2DM, were higher in obese Japanese subjects than in their nonobese counterparts similar to what is observed in Caucasian subjects. ${ }^{30}$ Unfortunately, in these studies, the findings were based on univariate analysis. For example, Iwao et al recently reported that obese subjects had higher levels of homeostatic model insulin resistance (HOMA-IR), higher homeostatic model assessment of $\beta$-cells (HOMA- $\beta$ ), and a higher insulinogenic index associated with a lower insulin sensitivity index in comparison with nonobese subjects at different stages of glucose tolerance in a univariate analysis. ${ }^{31}$ These data suggest that obese subjects have increased insulin resistance rather than reduced insulin secretion at all stages of glucose tolerance. Multiple logistic regression analysis showed that HOMA-IR was a significant independent factor between nonobese and obese subjects. Further, different therapeutic strategies should be considered in Japanese patients independent of obesity. ${ }^{31}$

\section{Effectiveness of incretin-based drugs for Japanese patients with T2DM}

The evidence suggests that Asian patients have a high risk of T2DM when compared with their Western counterparts at the same BMI, and are more prone to abdominal obesity and low muscle mass with increased insulin resistance. ${ }^{32}$

It has been noticed that incretin-based drugs are more effective in Asians, likely as a result of amelioration of defective early-phase insulin secretion, which is a characteristic feature of T2DM in Asians. ${ }^{27,33}$ Recent meta-analyses of DPP-4 inhibitor therapy support this notion. ${ }^{34,35}$ For Japanese patients, the $\mathrm{HbA}_{1 \mathrm{c}}$ reduction was twice that in non-Japanese patients when compared with placebo, without any increased risk of hypoglycemia. ${ }^{34}$ DPP-4 inhibitors were associated with a similar $\mathrm{HbA}_{1 \mathrm{c}}$ reduction or risk of hypoglycemia when compared with other hypoglycemic agents. Further, DPP-4 inhibitors have a significantly decreased risk of any adverse events and serious adverse events when compared with other hypoglycemic agents. ${ }^{34}$

Kim et al reported that when DPP-4 inhibitors were used as part of oral combination therapy, Asian-dominant studies showed a greater $\mathrm{HbA}_{1 \mathrm{c}}$-lowering effect than nonAsian-dominant studies (between-group difference $-0.18 \%$, $P=0.006) .{ }^{35}$ There was no relationship between BMI and the $\mathrm{HbA}_{1 \mathrm{c}}$-lowering efficacy of DPP-4 inhibitors in the studies in which mean BMI was $\geq 30 \mathrm{~kg} / \mathrm{m}^{2}$, but BMI was significantly associated with the $\mathrm{HbA}_{1 \mathrm{c}}$-lowering efficacy of DPP-4 inhibitors in studies in which mean BMI was $<30 \mathrm{~kg} / \mathrm{m}^{2}{ }^{25}$ There was no difference in body weight change from baseline between the Asian-dominant and non-Asian-dominant studies, which would indicate that the baseline BMI might influence the glucose-lowering action of DPP-4 inhibitors. ${ }^{35}$ One Japanese study confirmed a significant correlation $(r=0.419$, $P=0.0023$ ) between baseline BMI and $\mathrm{HbA}_{1 \mathrm{c}}$ levels after 16 weeks of treatment with sitagliptin in patients with T2DM and a BMI of $24.1 \pm 5.0 \mathrm{~kg} / \mathrm{m}^{2,36}$ indicating that a lower BMI might predict a good response to a DPP-4 inhibitor. Taken together, the different BMIs among ethnic groups might bring about the differences in the glucose-lowering response to DPP-4 inhibitors. ${ }^{35}$

On the other hand, Horikawa et al undertook a study of dietary intake in Japanese patients with T2DM to determine differences in diet between Japanese and Western subjects. Nutrition and food intake was investigated in 1,516 T2DM patients aged 40-70 years from outpatient clinics in 59 university and general hospitals using the Food Frequency Questionnaire in Japan. ${ }^{37}$ Mean energy intake for all subjects was $1,737 \pm 412 \mathrm{kcal} /$ day, and mean proportions of total protein, fat, and carbohydrate comprising total energy intake were $15.7 \%, 27.6 \%$, and $53.6 \%$, respectively. These patients expended a "low-fat energy-restricted diet" when compared with Western T2DM subjects, and their fat consumption was within the range traditionally recommended in Western countries. ${ }^{37}$ As a protein source, consumption of fish (100 g) and soybean products $(71 \mathrm{~g})$ was greater than that of meat $(50 \mathrm{~g})$ and eggs $(29 \mathrm{~g}) .{ }^{37}$ These outcomes would suggest that 
dietary content and food patterns among Japanese patients with T2DM might be quite close to those reported as being suitable for the prevention of obesity, T2DM, and cardiovascular disease, and for decreasing total mortality in Europe and the USA. ${ }^{37}$ These dietary differences between ethnic groups likely contribute to the observed ethnic differences in the glucose-lowering response to DPP-4 inhibitors.

A review by Wong et al reported that DPP-4 inhibitors and GLP-1 analogs were in general effective as add-on therapies to existing sulfonylureas, achieving $\mathrm{HbA}_{1 \mathrm{c}}$ reductions in the order of $0.59 \%-0.90 \%$ and $0.77 \%-1.62 \%$, respectively, in diabetic patients in the Asia-Pacific region. ${ }^{38}$ Few adverse events, including hypoglycemic attacks, were reported.

Therefore, these two new drug classes represent novel therapies with great potential to become major therapeutic options. ${ }^{38}$ Nevertheless, some of the limitations of these studies should be mentioned. In fact, almost all the studies were conducted among Japanese patients and few representations from other ethnic groups are available in the existing literature. This could be explained by the fact that Japanese patients with diabetes are in general less obese and have the "thrifty" genotype, which is associated with more insulin deficiency and less insulin resistance than the Western population. ${ }^{39}$ In fact, in a cross-sectional study of 17,000 Japanese patients with T2DM, 72\%-78\% of those on oral hypoglycemic agents were using sulfonylureas. ${ }^{40}$ Recently, Kozawa et al showed that endogenous insulinsecreting capacity, including insulinogenic index, fasting plasma C-peptide, and C-peptide index, was more sustained in DPP-4 inhibitor-effective patients than in DPP-4 inhibitorineffective patients. ${ }^{41}$ Moreover, insulin resistance evaluated by HOMA-IR was significantly higher in DPP-4 inhibitoreffective patients than in DPP-4 inhibitor-ineffective patients. In receiver operating characteristic analyses, the cut-off values for predicting the efficacy of DPP-4 inhibitors were 0.07 for insulinogenic index, $1.5 \mathrm{ng} / \mathrm{mL}$ for fasting plasma C-peptide, 1.0 for C-peptide index, $23.0 \mathrm{~kg} / \mathrm{m}^{2}$ for BMI, 1.3 for HOMA-IR, and 67.5 years for age. ${ }^{41}$

\section{Case report of saxagliptin in an obese patient with T2DM}

To determine whether saxagliptin would improve glycemic control and reduce insulin resistance, we investigated the effect of saxagliptin $5 \mathrm{mg}$ as monotherapy on blood glucose levels and the incretin response in an obese male patient with T2DM (age 39 years, BMI 27.5, HOMA-IR 3.57) during a $75 \mathrm{~g}$ oral glucose tolerance test. The test was performed at baseline and 2 months later, and levels of plasma glucose, immunoreactive insulin, C-peptide immunoreactivity, and glucagon were measured. Saxagliptin $5 \mathrm{mg}$ reduced the levels of plasma glucose, immunoreactive insulin, C-peptide immunoreactivity, and glucagon during the test. Saxagliptin also lowered $\mathrm{HbA}_{1 \mathrm{c}}$ (from $7.0 \%$ to $6.1 \%$ ) after 2 months. Saxagliptin may improve postprandial glycemic control via decreasing insulin resistance and glucagon secretion. Interestingly, immunoreactive insulin and C-peptide immunoreactivity levels were decreased after glucose loading in the $75 \mathrm{~g}$ oral glucose tolerance test performed in this obese patient with T2DM (Figure 1A-D).

\section{Clinical development study in Japan also supports its usefulness for T2DM \\ Multiple dose monotherapy trial}

In a multicenter, randomized, double-blind, placebocontrolled, multiple-dose Phase II trial, 349 Japanese patients with T2DM who had inadequate glycemic control on a combination of diet and exercise therapy with or without oral hypoglycemic agent monotherapy were assigned to receive oral doses of saxagliptin $1,2.5$, or $5 \mathrm{mg}$ or placebo (93 patients, 88 patients, 81 patients, and 87 patients, respectively) once daily before breakfast for 12 weeks, after a 2-week placebo run-in period (Table 1). ${ }^{42,43}$ Age, sex, BMI, $\mathrm{HbA}_{1 \mathrm{c}}$, fasting plasma glucose, fasting glycoalbumin, fasting immunoreactive insulin, fasting C-peptide immunoreactivity, HOMA- $\beta$, and HOMA-IR were not significantly different between the groups treated with saxagliptin 1, 2.5, and $5 \mathrm{mg}$, and placebo. There were no significant differences that prescription condition (assortment, use frequency) of a pre-treatment drug for T2DM, such as sulfonylureas, biguanides, $\alpha$-glycosidase inhibitors, TZDs, and glinides among the groups treated with saxagliptin 1, 2.5, and $5 \mathrm{mg}$, and placebo. (Table 2). Patients with T2DM who received oral hypoglycemic monotherapy (except for those taking TZDs) after an 8-week washout period, or patients with TZD monotherapy had a 12 -week washout period, the patients who had a fluctuation in $\mathrm{HbA}_{1 \mathrm{c}}$ of $1.0 \%$ or less, were eligible to participate in this study (Table 2). One patient in the 5 mg group was excluded from the efficacy analysis because $\mathrm{HbA}_{1 \mathrm{c}}$ values had not been recorded. Changes in $\mathrm{HbA}_{1 \mathrm{c}}$, fasting plasma glucose, and glycoalbumin from baseline to 12 weeks were compared between saxagliptin and placebo using Dunnett's test. The last observation carried forward method was used to handle data missing because of early discontinuation or data censoring. In this multiple dose 
A

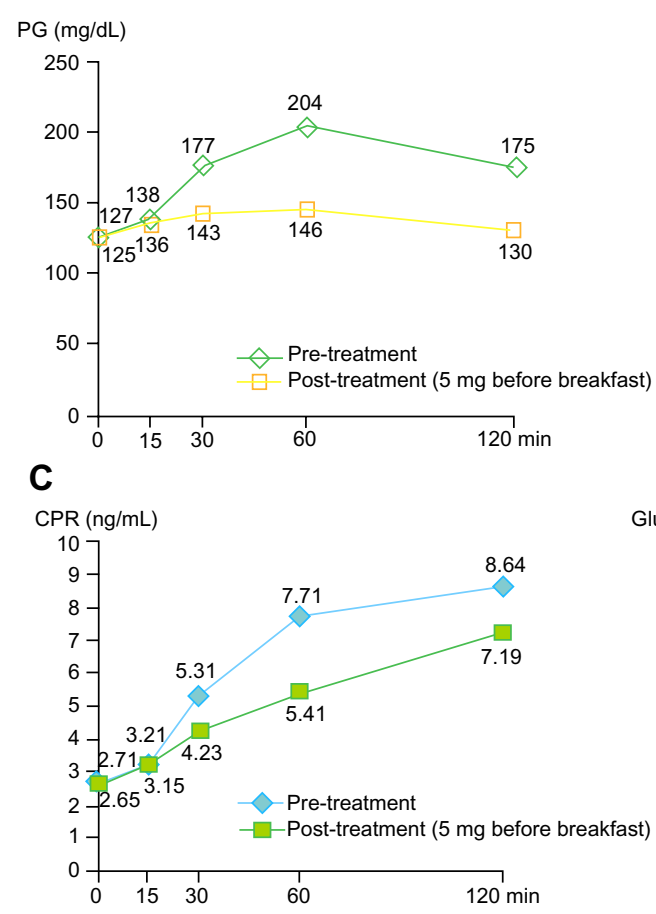

B

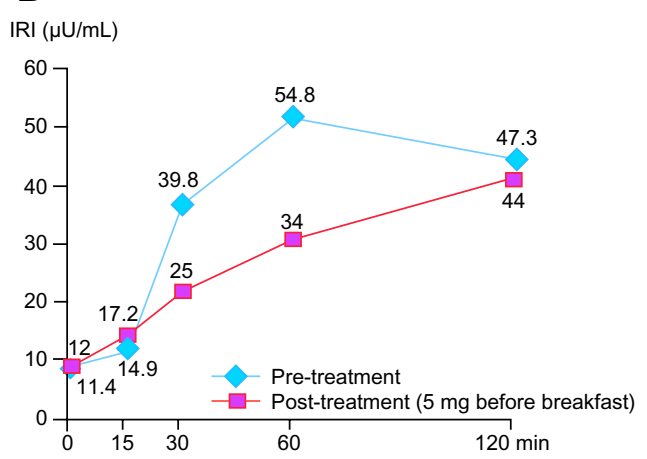

D

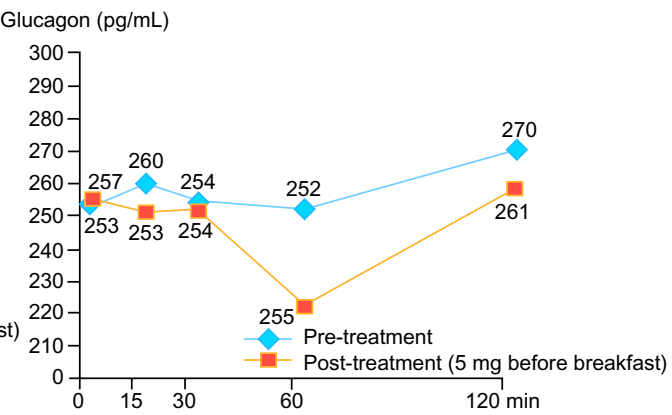

Figure I Beneficial effects of saxagliptin on PG (A), IRI (B), CPR (C), and glucagon (D) in $75 \mathrm{~g}$ oral glucose tolerance test for an obese patient with types 2 diabetes mellitus. Abbreviations: IRI, immunoreactive insulin; CPR, plasma C-peptide; PG, plasma glucose; min, minutes.

study, saxagliptin achieved consistent reductions in $\mathrm{HbA}_{1 \mathrm{c}}$ from baseline to 12 weeks (Figure 2A). By 12 weeks, $\mathrm{HbA}_{1 \mathrm{c}}$ had decreased by $0.59 \%$ from a baseline value of $8.69 \%$ in patients receiving saxagliptin $1 \mathrm{mg}(\mathrm{n}=93)$, by $0.69 \%$ from a baseline of $8.40 \%$ in patients receiving $2.5 \mathrm{mg}(\mathrm{n}=88)$, by $0.90 \%$ from a baseline of $8.47 \%$ in patients receiving $5 \mathrm{mg}$ $(n=81)$, and by $0.08 \%$ from a baseline of $8.47 \%$ in patients receiving placebo $(n=87)$. The adjusted between-treatment difference (saxagliptin 1, 2.5, and $5 \mathrm{mg}$ versus placebo) was statistically significant $(P<0.0001)$ in favor of saxagliptin (Figure 2B). ${ }^{42,43}$ After 12 weeks of treatment, fasting plasma glucose had decreased by $12.6 \mathrm{mg} / \mathrm{dL}$ from a baseline value of $173.6 \mathrm{mg} / \mathrm{dL}$ in patients receiving saxagliptin $1 \mathrm{mg}$ ( $\mathrm{n}=93$ ), by $12.0 \mathrm{mg} / \mathrm{dL}$ from a baseline of $166.8 \mathrm{mg} / \mathrm{dL}$ in patients receiving $2.5 \mathrm{mg}(\mathrm{n}=88)$, and by $16.6 \mathrm{mg} / \mathrm{dL}$ from a baseline of $162.5 \mathrm{mg} / \mathrm{dL}$ in patients receiving $5 \mathrm{mg}$ $(\mathrm{n}=81)$, and increased by $0.9 \mathrm{mg} / \mathrm{dL}$ from a baseline of $167.3 \mathrm{mg} / \mathrm{dL}$ in patients receiving placebo $(\mathrm{n}=86)$. The

Table I Baseline patient characteristics in multiple dose trial

\begin{tabular}{|c|c|c|c|c|}
\hline & \multicolumn{3}{|c|}{ Saxagliptin group } & \multirow{2}{*}{$\begin{array}{l}\text { Placebo } \\
\text { group }(n=87)\end{array}$} \\
\hline & I mg (n=93) & $2.5 \mathrm{mg}(\mathrm{n}=88)$ & $5 \mathrm{mg}(\mathrm{n}=82)$ & \\
\hline Age (year) & $57.0 \pm 10.9$ & $56.3 \pm 9.7$ & $57.7 \pm 10.2$ & $58.7 \pm 9.0$ \\
\hline Male, n (\%) & $61(65.6)$ & $59(67.0)$ & $55(67.1)$ & $57(65.5)$ \\
\hline BMI $\left(\mathrm{kg} / \mathrm{m}^{2}\right)$ & $24.70 \pm 4.25$ & $25.5 I \pm 4.19$ & $24.82 \pm 3.92$ & $24.68 \pm 5.06$ \\
\hline Duration of T2DM (year) & $5.55 \pm 5.27$ & $4.98 \pm 4.34$ & $5.25 \pm 5.09$ & $4.96 \pm 4.14$ \\
\hline $\mathrm{HbA}_{\mathrm{lc}}(\mathrm{NGSP})(\%)$ & $8.69 \pm 0.76$ & $8.40 \pm 0.76$ & $8.47 \pm 0.77$ & $8.05 \pm 0.71$ \\
\hline Fasting plasma glucose $(\mathrm{mg} / \mathrm{dL})$ & $173.6 \pm 35.7$ & $166.8 \pm 32.5$ & $162.4 \pm 29.8$ & $168.2 \pm 35.9$ \\
\hline Fasting glycoalbumin (\%) & $24.59 \pm 4.32$ & $23.54 \pm 3.66$ & $23.20 \pm 3.10$ & $24.37 \pm 4.24$ \\
\hline Fasting IRI $(\mu \mathrm{U} / \mathrm{mL})$ & $6.91 \pm 4.80$ & $7.01 \pm 4.28$ & $6.98 \pm 6.24$ & $6.78 \pm 4.79$ \\
\hline Fasting CPR (ng/mL) & $2.33 \pm 0.89$ & $2.4 I \pm 0.88$ & $2.36 \pm 0.92$ & $2.33 \pm 0.87$ \\
\hline HOMA- $\beta$ (\%) & $24.32 \pm 17.20$ & $26.25 \pm 17.93$ & $27.40 \pm 30.44$ & $25.5 I \pm 19.86$ \\
\hline HOMA-R & $2.99 \pm 2.30$ & $2.91 \pm 1.87$ & $2.80 \pm 2.31$ & $2.80 \pm 2.03$ \\
\hline
\end{tabular}

Notes: Values are mean \pm SD. Because prior to the start of the test, $\mathrm{HbA}_{\mathrm{lc}}$ data was not obtained after administration, one case of 5 mg group was excluded from the analysis of target efficacy.

Abbreviations: BMI, body mass index; T2DM, type 2 diabetes mellitus; IRI, immunoreactive insulin; CPR, plasma C-peptide; HbA homeostatic model insulin resistance; HOMA- $\beta$, homeostatic model assessment of $\beta$-cells; SD, standard deviation; NGSP, National Glycohemoglobin Standardization Program. 
Table 2 Patient use of oral hypoglycemic agents before saxagliptin treatment in multiple dose trial

\begin{tabular}{|c|c|c|c|c|}
\hline & \multicolumn{3}{|c|}{ Saxagliptin group } & \multirow{2}{*}{$\begin{array}{l}\text { Placebo } \\
\text { group } \\
(n=87)\end{array}$} \\
\hline & $\begin{array}{l}I \mathrm{mg} \\
(\mathrm{n}=93)\end{array}$ & $\begin{array}{l}2.5 \mathrm{mg} \\
(\mathrm{n}=88)\end{array}$ & $\begin{array}{l}5 \mathrm{mg} \\
(\mathrm{n}=82)\end{array}$ & \\
\hline \multicolumn{5}{|l|}{ OHA, n (\%) } \\
\hline None & $59(63.4)$ & $60(68.2)$ & $61(74.4)$ & $62(7 \mid .3)$ \\
\hline $\mathrm{OHA}$ & $34(36.6)$ & $28(31.8)$ & $21(25.6)$ & $25(28.7)$ \\
\hline SUs & $14(15.1)$ & $12(13.6)$ & $8(9.8)$ & $8(9.2)$ \\
\hline Biguanides & $8(8.6)$ & $7(8.0)$ & $9(I 1.0)$ & $5(5.7)$ \\
\hline$\alpha$-Gls & $4(4.3)$ & $4(4.5)$ & $3(3.7)$ & $7(8.0)$ \\
\hline TZDs & $2(2.2)$ & $2(2.3)$ & $0(0.0)$ & $3(3.4)$ \\
\hline Glinides & $7(7.5)$ & $3(3.4)$ & I (I.2) & $2(2.3)$ \\
\hline
\end{tabular}

Abbreviations: OHA, oral hypoglycemic agents; $\mathrm{SUs}$, sulfonylureas; TZDs, thiazolidinediones; $\alpha$-Gls, $\alpha$-glycosidase inhibitors.

adjusted between-treatment difference (saxagliptin 1, 2.5 , and $5 \mathrm{mg}$ versus placebo) was statistically significant $(P<0.0001)$ in favor of saxagliptin. ${ }^{42,43}$ After 12 weeks of treatment, glycoalbumin had decreased by $0.76 \%$ from a baseline value of $24.59 \%$ in patients receiving saxagliptin 1 $\mathrm{mg}(\mathrm{n}=93)$, by $1.27 \%$ from a baseline of $23.54 \%$ in patients receiving $2.5 \mathrm{mg}(\mathrm{n}=88)$, and by $1.96 \%$ from a baseline of $23.18 \%$ in patients receiving $5 \mathrm{mg}(\mathrm{n}=81)$, and increased by $1.28 \%$ from a baseline of $24.25 \%$ in patients receiving placebo $(\mathrm{n}=86)$. The adjusted between-treatment difference (saxagliptin $1,2.5$, and $5 \mathrm{mg}$ versus placebo) was statistically significant $(P<0.0001)$ in favor of saxagliptin. ${ }^{42,43}$ In the saxagliptin treatment groups, significant reductions in $\mathrm{HbA}_{1 \mathrm{c}}$, fasting plasma glucose, and glycoalbumin were observed regardless of dose when compared with placebo, with the highest efficacy observed in the $5 \mathrm{mg}$ dose group. ${ }^{42,43}$

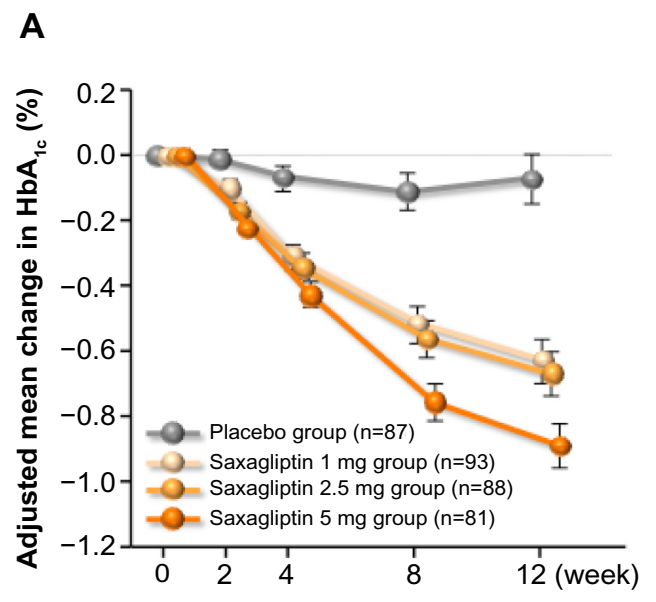

Saxagliptin 1, 2.5, and $5 \mathrm{mg}$ has led to significant improvements in the glycemic indices of $\mathrm{HbA}_{1 \mathrm{c}}$, fasting plasma glucose, and glycoalbumin, and has been generally safe and well tolerated in T2DM. ${ }^{42,43}$ The overall incidence of adverse events on saxagliptin $1 \mathrm{mg}(44.1 \%)$, saxagliptin $2.5 \mathrm{mg}(45.5 \%)$, and saxagliptin $5 \mathrm{mg}(47.6 \%)$ were comparable with placebo (54.0\%). The most frequent adverse events were nasopharyngitis (one case in the $1 \mathrm{mg}$ group, nine cases in the $2.5 \mathrm{mg}$ group, six cases in the $5 \mathrm{mg}$ group). The main adverse effects in the saxagliptin group were abdominal distension (three cases, $1.1 \%$ ) and pruritus (three cases, $1.1 \%$ ). The proportion of patients who experienced hypoglycemic events was low in the $2.5 \mathrm{mg}$ group (0.4\%). The incidence of adverse events in the saxagliptin groups did not tend to increase in a dose-dependent manner. ${ }^{42,43}$

\section{Long-term monotherapy trial}

In a multicenter, open-label, noncontrolled Phase III trial, 125 Japanese patients with T2DM and inadequate glycemic control were assigned to receive oral doses of saxagliptin $5 \mathrm{mg}$ once daily before breakfast for 52 weeks, ${ }^{42,44}$ (Table 3) which induced a sustained reduction in $\mathrm{HbA}_{1 \mathrm{c}}$ (Figure 3). Saxagliptin $5 \mathrm{mg}$ also induced a sustained reduction in fasting plasma glucose and did not affect body weight during the study period.

Long-term monotherapy with saxagliptin $5 \mathrm{mg}$ achieved sustained glycemic control and was safe and well tolerated for up to 52 weeks. ${ }^{42,44}$ The overall incidence of adverse events was $78.4 \%$. The most frequent adverse event was nasopharyngitis (37 cases, 29.6\%). Serious adverse events

\section{B}

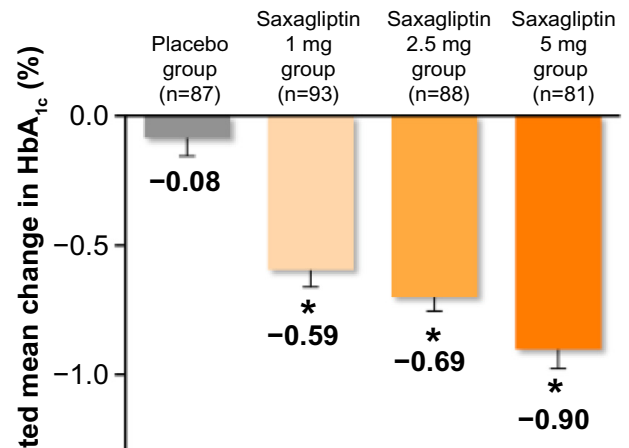

Mean $\mathrm{HbA}_{1 \mathrm{c}}$ at baseline (NGSP) Placebo group: $8.47 \%$

Saxagliptin 1 mg group: $8.69 \%$ Saxagliptin 2.5 mg group: $8.40 \%$ Saxagliptin 5 mg group: $8.47 \%$

Figure 2 Mean change of $\mathrm{HbA}_{\mathrm{Ic}}$ (last observation carried forward) in multiple dose study. (A) Adjusted mean change in $\mathrm{HbA} \mathrm{Ic}_{\mathrm{lc}}$ over time and (B) adjusted mean change in $\mathrm{HbA}_{\mathrm{lc}}$ from baseline to 12 weeks.

Notes: Values are mean $\pm S E$. $* P<0.000$ I versus placebo, Dunnett's test.

Abbreviations: $\mathrm{HbA}_{I c}$, glycated hemoglobin; SE, standard error of the mean; NGSP, National Glycohemoglobin Standardization Program. 
Table 3 Baseline patient characteristics in saxagliptin 5 mg longterm monotherapy trial

\begin{tabular}{ll}
\hline & $\begin{array}{l}\text { Saxagliptin } \mathbf{5 ~} \mathbf{~ m g} \\
\text { group }(\mathbf{n}=\mathbf{I 2 5})\end{array}$ \\
\hline Age (year) & $58.4 \pm 10.3$ \\
Sex, $\mathrm{n}(\%)$ & \\
Male & $80(64.0)$ \\
Female & $45(36.0)$ \\
BMI $\left(\mathrm{kg} / \mathrm{m}^{2}\right)$ & $25.36 \pm 3.84$ \\
Duration of T2DM (year) & $3.93 \pm 3.45$ \\
HbA Ic $_{\text {NGSP) }(\%)}$ & $8.25 \pm 0.93$ \\
Fasting plasma glucose (mg/dL) & $158.2 \pm 30.5$ \\
Diabetic complication, $\mathrm{n}(\%)$ & \\
Absence & $92(73.6)$ \\
Presence & $33(26.4)$ \\
Diabetic neuropathy & $4(3.2)$ \\
Diabetic retinopathy & $12(9.6)$ \\
Diabetic nephropathy & $9(7.2)$ \\
Others & $18(14.4)$ \\
\hline
\end{tabular}

Note: Values are mean \pm SD.

Abbreviations: BMI, body mass index; T2DM, type 2 diabetes mellitus; NGSP, National Glycohemoglobin Standardization Program; $\mathrm{HbA}_{\mathrm{lc}}$, glycated hemoglobin; $\mathrm{SD}$, standard deviation.

were observed in six cases $(4.8 \%)$, it could not be denied that there would be the causal relationship to saxagliptin with each one case of asymptomatic myocardial infarction, polymyalgia rheumatica. The incidence of side effects was $15.2 \%$, the main ones being two cases of frequent urination (1.6\%). No hypoglycemic events were reported. ${ }^{42,44}$

\section{Long-term combination therapy trial}

In a multicenter, open-label, non-controlled Phase III trial, 577 Japanese patients with T2DM who had inadequate glycemic control on a combination of diet and exercise therapy with one or more oral hypoglycemic combination therapy group (CTG), ie, sulfonylureas, $\alpha$-glycosidase inhibitors, biguanides, TZDs, or glinides, were assigned to receive oral doses of saxagliptin $5 \mathrm{mg}$ combined with sulfonylureas $(n=182), \alpha$-glycosidase inhibitors $(n=111)$, biguanides $(n=116)$, TZDs $(n=108)$, or glinides $(n=57)$ once daily before breakfast for 52 weeks (Table 4). ${ }^{42,45}$ Patients with T2DM who had been on oral hypoglycemic monotherapy for 12 weeks were considered for participation in this study. When patients with T2DM who had two or more oral hypoglycemic agents (except for patients taking TZDs), the patients were eligible to participate in this study after an 8 -week washout period in the protocol. In actuality, patients with T2DM who had two or more oral hypoglycemic agents including TZDs, could not washout TZDs. On the other hand, when T2DM patients who had sulfonylurea combination therapy, they reduced the sulfonylurea dose from 8 weeks before saxagliptin treatment. Changes in $\mathrm{HbA}_{1 \mathrm{c}}$, fasting plasma glucose, and 1,5-anhydroglucitol (1,5-AG) from baseline to 52 weeks compared between post-treatment with saxagliptin and baseline using a paired Student's t-test. Differences were considered significant at $P<0.05$.

After 52 weeks of treatment, $\mathrm{HbA}_{1 \mathrm{c}}$ had decreased by $0.50 \%$ from a baseline value of $8.46 \%$ in isulfonylureas CTG patients, by $0.83 \%$ from a baseline of $8.59 \%$ in $\alpha$-glycosidase inhibitors CTG patients, by $0.64 \%$ from a baseline of $8.50 \%$ in biguanides CTG patients, by $0.51 \%$ from a baseline of $8.65 \%$ in TZDs CTG patients, and by $0.60 \%$ from a baseline of $8.22 \%$ in glinides CTG patients

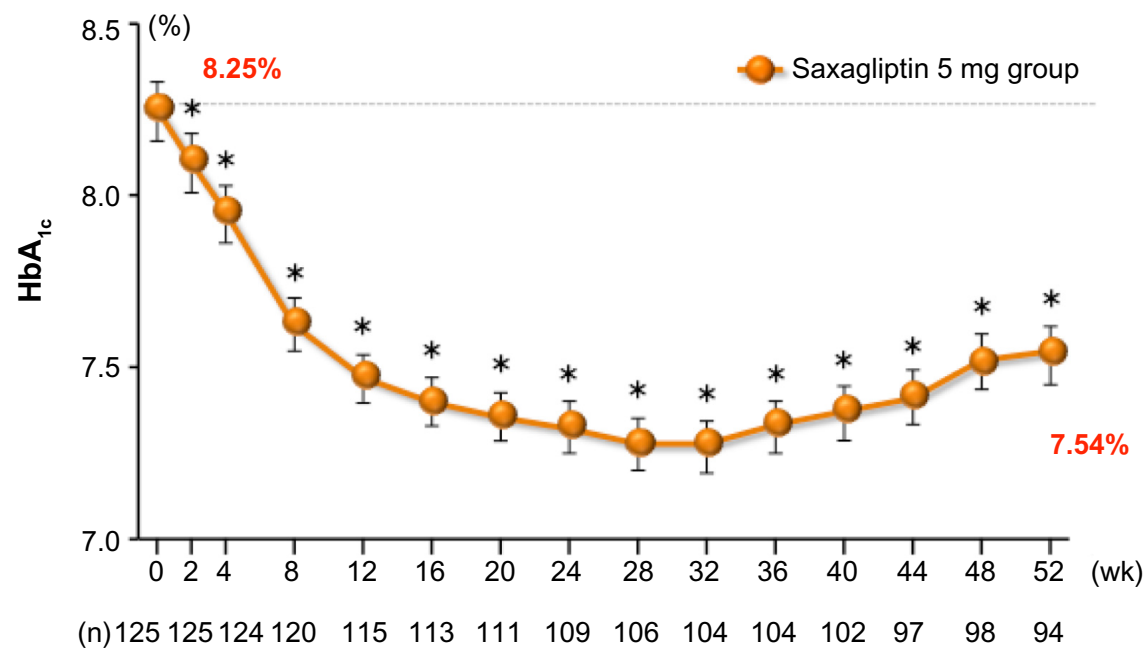

Figure 3 Adjusted mean change in $\mathrm{HbA}_{\mathrm{lc}}$ over time in saxagliptin $5 \mathrm{mg}$ long-term monotherapy trial.

Notes: Values are mean $\pm S E$. $* P<0.05$ versus baseline, paired Student's $t$-test.

Abbreviations: $\mathrm{HbA}_{\mathrm{lc}}$, glycated hemoglobin; $\mathrm{SE}$, standard error of the mean; wk, weeks. 
Table 4 Baseline patient characteristics in saxagliptin 5 mg long-term combination therapy trials

\begin{tabular}{|c|c|c|c|c|c|}
\hline & $\begin{array}{l}\text { SUs }+ \\
\text { saxagliptin } \\
5 \mathrm{mg}(\mathrm{n}=\mid 83)\end{array}$ & $\begin{array}{l}\alpha \text {-Gls }+ \\
\text { saxagliptin } \\
5 \text { mg }(n=|| 3)\end{array}$ & $\begin{array}{l}\text { Biguanides }+ \\
\text { saxagliptin } \\
5 \mathrm{mg}(\mathrm{n}=1 \mathrm{16})\end{array}$ & $\begin{array}{l}\text { TZDs }+ \\
\text { saxagliptin } \\
5 \text { mg }(n=108)\end{array}$ & $\begin{array}{l}\text { Glinides + } \\
\text { saxagliptin } \\
5 \mathrm{mg}(\mathrm{n}=57)\end{array}$ \\
\hline Age (year) & $62.2 \pm 9.5$ & $59.1 \pm 11.3$ & $57.4 \pm 10.2$ & $57.2 \pm 10.6$ & $60.9 \pm 11.4$ \\
\hline Male, n (\%) & $116(63.7)$ & $75(67.6)$ & $7 I(6 I .2)$ & $76(70.4)$ & $4(59.6)$ \\
\hline BMI $\left(\mathrm{kg} / \mathrm{m}^{2}\right)$ & $24.4 I \pm 3.80$ & $24.38 \pm 4.34$ & $26.50 \pm 4.37$ & $27.54 \pm 5.99$ & $25.61 \pm 4.47$ \\
\hline Duration of T2DM (year) & $10.10 \pm 6.97$ & $8.10 \pm 6.44$ & $7.20 \pm 5.19$ & $7.95 \pm 5.81$ & $7.03 \pm 6.89$ \\
\hline $\mathrm{HbA}_{\mathrm{lc}}(\%)$ & $8.46 \pm 0.72$ & $8.59 \pm 0.88$ & $8.50 \pm 0.81$ & $8.65 \pm 0.96$ & $8.22 \pm 0.67$ \\
\hline Fasting plasma glucose $(\mathrm{mg} / \mathrm{dL})$ & $162.0 \pm 33.3$ & $179.6 \pm 39.2$ & $168.8 \pm 35.9$ & $177.9 \pm 40.7$ & $159.8 \pm 30.2$ \\
\hline I.5-AG $(\mu \mathrm{U} / \mathrm{mL})$ & $4.70 \pm 3.20$ & $6.25 \pm 5.20$ & $5.29 \pm 4.21$ & $3.96 \pm 3.4 I$ & $6.45 \pm 4.10$ \\
\hline HOMA- $\beta$ (\%) & $29.58 \pm 25.10$ & $23.89 \pm 19.00$ & $34.31 \pm 27.16$ & $24.99 \pm 19.85$ & $37.89 \pm 35.31$ \\
\hline HOMA-IR & $2.91 \pm 2.27$ & $3.13 \pm 2.31$ & $3.74 \pm 2.39$ & $3.28 \pm 2.94$ & $3.74 \pm 3.89$ \\
\hline \multicolumn{6}{|l|}{ Diabetic complication, n (\%) } \\
\hline Presence & $91(50.0)$ & $49(44.1)$ & $60(51.7)$ & $55(50.9)$ & $34(59.6)$ \\
\hline Diabetic neuropathy & $34(18.7)$ & $15(13.5)$ & $21(18.1)$ & $18(16.7)$ & $14(24.6)$ \\
\hline Diabetic retinopathy & $34(18.7)$ & $13(11.7)$ & $17(14.7)$ & $19(17.6)$ & $10(17.5)$ \\
\hline Diabetic nephropathy & $53(29.1)$ & $32(28.8)$ & $40(34.5)$ & $35(32.4)$ & $18(31.6)$ \\
\hline Others & $7(3.8)$ & $0(0.0)$ & $2(1.7)$ & $2(1.9)$ & $\mathrm{I}(\mathrm{I} .8)$ \\
\hline \multicolumn{6}{|c|}{ Complications of cardiovascular disease, $\mathrm{n}(\%)$} \\
\hline Presence & $26(14.3)$ & $6(5.4)$ & $12(10.3)$ & II (I0.2) & II (19.3) \\
\hline
\end{tabular}

Note: Values are mean \pm SD.

Abbreviations: BMI, body mass index; T2DM, type 2 diabetes mellitus; HbA , glycated hemoglobin; HOMA-IR, homeostatic model insulin resistance; HOMA- $\beta$, homeostatic model assessment of $\beta$-cells; SD, standard deviation; SUs, sulfonylureas; TZDs, thiazolidinediones; $\alpha$-Gls, $\alpha$-glycosidase inhibitors; I,5-AG, I,5-anhydroglucitol.

(Figure 4A-D). The adjusted between-treatment difference was statistically significant $(P<0.05)$ in favor of saxagliptin (Figure 5). ${ }^{42,45}$ After 52 weeks of treatment, fasting plasma glucose had decreased by $10.7 \mathrm{mg} / \mathrm{dL}$ from a baseline value of $162.0 \mathrm{mg} / \mathrm{dL}$ in sulfonylureas CTG patients, by $23.8 \mathrm{mg} / \mathrm{dL}$ from a baseline of $179.6 \mathrm{mg} / \mathrm{dL}$ in $\alpha$-glycosidase inhibitors CTG patients, by $15.2 \mathrm{mg} / \mathrm{dL}$ from a baseline of
$168.8 \mathrm{mg} / \mathrm{dL}$ in biguanides CTG patients, by $11.4 \mathrm{mg} / \mathrm{dL}$ from a baseline of $177.9 \mathrm{mg} / \mathrm{dL}$ in TZDs CTG patients, and by $13.2 \mathrm{mg} / \mathrm{dL}$ from a baseline of $159.8 \mathrm{mg} / \mathrm{dL}$ in glinides CTG patients. ${ }^{42,45}$

After 52 weeks of treatment, 1,5-AG had increased by $2.9 \mu \mathrm{g} / \mathrm{mL}$ from a baseline value of $4.7 \mu \mathrm{g} / \mathrm{mL}$ in sulfonylureas CTG patients, by $5.25 \mu \mathrm{g} / \mathrm{mL}$ from a baseline of
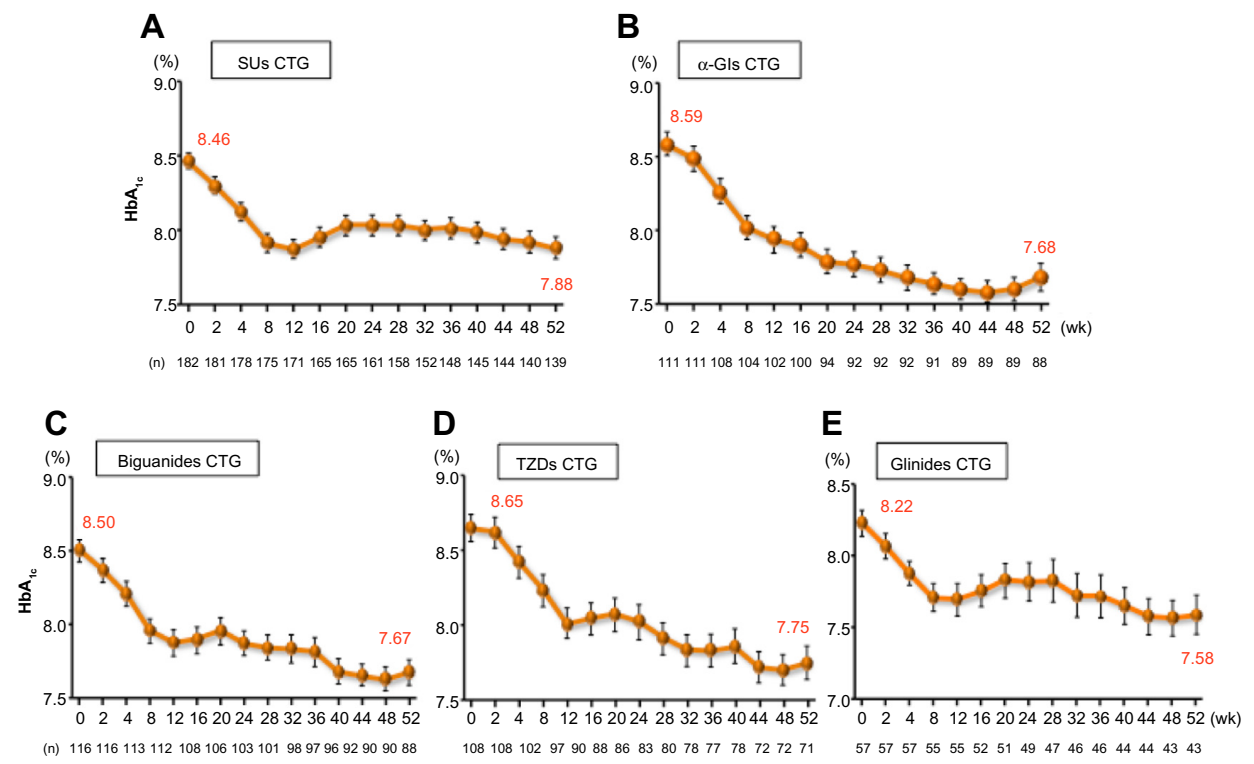

Figure 4 Changes of $\mathrm{HbA}_{\mathrm{Ic}}$ in saxagliptin $5 \mathrm{mg}$ long-term combination therapy trial (A) SUs CTG, (B) $\alpha$-Gls CTG, (C) biguanides CTG, (D) TZDs CTG, and (E) glinides CTG. Note: Values are mean \pm SE

Abbreviations: $\mathrm{CTG}$, combination therapy group; SUs, sulfonylureas;TZDs, thiazolidinediones; $\alpha$-Gls, $\alpha$-glycosidase inhibitors; $S E$, standard error of the mean; $\mathrm{HbA}$ Ic , $\delta$ lycated hemoglobin; wk, weeks. 


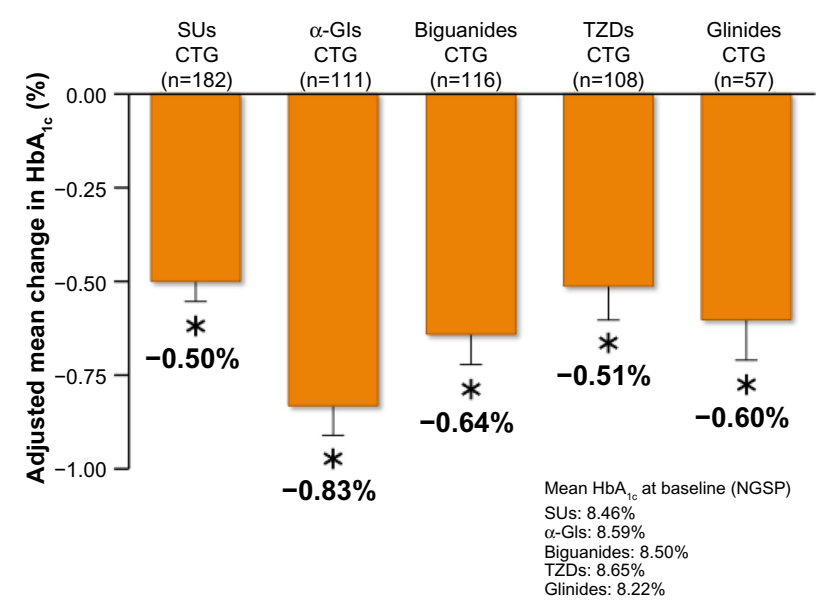

Figure 5 Adjusted mean change in $\mathrm{HbA}_{\mathrm{lc}}$ from baseline to 52 week in saxagliptin $5 \mathrm{mg}$ long-term combination therapy trial.

Note: Values are mean \pm SE. $* P<0.05$ versus baseline, paired Student's $t$-test. Abbreviations: CTG, combination therapy group; SUs, sulfonylureas; TZDs, thiazolidinediones; $\alpha$-Gls, $\alpha$-glycosidase inhibitors; SE, standard error of the mean; $\mathrm{HbA}_{I c}$, glycated hemoglobin; NGSP, National Glycohemoglobin Standardization Program.

$6.25 \mu \mathrm{g} / \mathrm{mL}$ in $\alpha$-glycosidase inhibitors CTG patients, by $3.67 \mu \mathrm{g} / \mathrm{mL}$ from a baseline of $5.29 \mu \mathrm{g} / \mathrm{mL}$ in biguanides CTG patients, by $3.33 \mu \mathrm{g} / \mathrm{mL}$ from a baseline of $3.96 \mu \mathrm{g} / \mathrm{mL}$ in TZDs CTG patients, and by $3.88 \mu \mathrm{g} / \mathrm{mL}$ from a baseline of $6.45 \mu \mathrm{g} / \mathrm{mL}$ in glinides CTG patients. ${ }^{40}$ These data suggest that saxagliptin clearly improves fasting and postprandial hyperglycemia in patients with T2DM. Long-term combination therapy with saxagliptin and other oral hypoglycemic agents provided sustained glycemic control and was well tolerated for up to 52 weeks. ${ }^{42,45}$

The overall incidence of adverse events was $84.2 \%$ for sulfonylureas CTG patients, $77.0 \%$ for $\alpha$-glycosidase inhibitors CTG patients, $77.6 \%$ for biguanides CTG patients, $79.6 \%$ for TZDs CTG patients, and $84.2 \%$ for glinides CTG patients. There were no differences with regard to incidence of adverse events among the CTG patients, the most frequent adverse event being nasopharyngitis (in $22.1 \%-36.8 \%$ of patients). Serious adverse events were observed in nine (4.9\%) sulfonylureas CTG patients, nine ( $8.0 \%) \alpha$-glycosidase inhibitors CTG patients, two (1.7\%) biguanides CTG patients, four (3.7\%) TZDs CTG patients, and six (10.5\%) glinides CTG patients. Severe hypoglycemia was not observed. ${ }^{42,45}$ The incidence of adverse events related to hypoglycemia was low in $\alpha$-glycosidase inhibitors CTG patients $(0.9 \%)$, in biguanides CTG patients (1.7\%), and in TZDs CTG patients $(1.9 \%)$, and there was no difference between these hypoglycemic agent CTG and long-term saxagliptin monotherapy. However, the incidence of adverse events related to hypoglycemia was higher in sulfonylureas CTG patients $(8.2 \%)$ and in glinides CTG patients (10.5\%) than saxagliptin long-term monotherapy, other oral hypoglycemic agent CTG patients. Thus, saxagliptin as an add-on to sulfonylureas or glinides has a tendency to increase hypoglycemia, but not when combined with other oral hypoglycemic agents, such as $\alpha$-glycosidase inhibitors, biguanides, or TZDs.

The results of the above clinical trials confirmed the longterm efficacy and safety of saxagliptin as monotherapy and as add-on combination therapy, and support its usefulness as a therapeutic agent for Japanese patients with T2DM. Saxagliptin has less concern for hypoglycemia and weight gain, which often become problematic in routine care..$^{42-45}$

\section{Meta-analysis of SAVOR-TIMI 53 and EXAMINE trials}

Meta-analysis of clinical trials in the USA showed no evidence of an increased risk of cardiovascular events being associated with saxagliptin, suggesting superiority of this agent in terms of safety. ${ }^{46}$

The multicenter, randomized, double-blind, placebocontrolled, Phase IV SAVOR-TIMI (Saxagliptin Assessment of Vascular Outcomes Recorded in Patients with Diabetes Mellitus-Thrombolysis in Myocardial Infarction) 53 study, ${ }^{47,48}$ conducted in 26 countries, reported a lower $\mathrm{HbA}_{1 \mathrm{c}}$ level in patients receiving saxagliptin when compared with a placebo group. This study included a total of 16,496 diabetic patients from mainly Western countries (91.7\%). Despite significant improvements in glycemic control being observed, this study failed to show any cardioprotective benefit. Saxagliptin was found to be noninferior to placebo for cardiovascular endpoints, although the rate of hospitalization for heart failure was increased. ${ }^{48}$

Although saxagliptin improves glycemic control, other approaches with longer observation periods are necessary to reduce cardiovascular risk in patients with T2DM. Results similar to the above study were reported in the recent EXAMINE (EXamination of cArdiovascular outcoMes:AlogliptIN versus standard of carE in patients with type 2 diabetes mellitus and acute coronary syndrome) trial (ClinicalTrials.gov identifier NCT00968708). This trial recruited patients from different geographic regions, for which the Asia-Pacific region accounted for around $20 \%$ of the total study population. No differences were observed in the primary endpoints of cardiovascular death, myocardial infarction, and stroke between the alogliptin and placebo groups. In particular, the rates of primary endpoint among subjects in Asia/Pacific region were $9.1 \%$ and $10.3 \%$ in the alogliptin and placebo groups, respectively ( $95 \%$ confidence interval [CI] 0.59-1.30). ${ }^{49}$ 
In an editorial, Schernthaner and Sattar discussed the cardiovascular events reported in SAVOR-TIMI and EXAMINE. ${ }^{50}$ Patients randomized to active therapy or placebo in the SAVOR-TIMI and EXAMINE studies differed in many aspects. Whereas SAVOR-TIMI recruited two types of patients, one group with established cardiovascular disease and the other with multiple risk factors, all patients in EXAMINE had a history of acute coronary syndrome. ${ }^{48,49}$ Thus, prior stroke and peripheral arterial disease was appreciably less common in EXAMINE, and whereas heart failure at baseline was documented in $28 \%$ of patients included in EXAMINE, it was present in only $14.8 \%$ and $5.1 \%$, respectively, of the two groups of patients recruited into SAVOR-TIMI. About two thirds of all subjects received metformin at baseline, and sulfonylureas were used by $37 \%-46 \%$ of participants. Insulin was used more often in SAVOR-TIMI patients with established cardiovascular disease (42.2\%) compared with patients included in EXAMINE (30\%), which is likely explained in part by the fact that the median duration of diabetes was longer in SAVOR-TIMI than in EXAMINE (10.3 versus 7.3 years). Treatment for lowering of cardiovascular risk factors was very good in both trials; statins and angiotensin-converting enzyme inhibitors/angiotensin receptor blockers were used in $80 \%-90 \%$ of subjects and antiplatelet agents in $89 \%-97 \%$; however, $\beta$-blocker were less used in SAVOR-TIMI than in EXAMINE (68\% versus $82 \%$ ). As expected, the $25 \%$ of subjects in SAVOR-TIMI presenting with multiple risk factors received less cardioprotective therapy.

The SAVOR-TIMI study was basically designed as a superiority study testing the hypothesis that treatment with saxagliptin is safe and decreases cardiovascular events in high-risk patients with $\mathrm{T} 2 \mathrm{DM},{ }^{48}$ whereas the primary objective of EXAMINE was to demonstrate the noninferiority of major adverse cardiac events on alogliptin versus placebo in the treatment of T2DM in a patient group at high cardiovascular risk. ${ }^{49}$ The primary endpoint, ie, the composite of death from cardiovascular causes, nonfatal myocardial infarction, or nonfatal stroke, was not different between the DPP-4 inhibitor and placebo arms either SAVOR-TIMI or EXAMINE, despite the small difference in median exposure time (25 months versus 18 months). These findings demonstrate that saxagliptin and alogliptin are safe in terms of cardiovascular disease, but cannot further lower the risk of the primary endpoint when added to other antidiabetic and cardioprotective drugs in patients with T2DM at high cardiovascular risk. ${ }^{50}$ The $\mathrm{HbA}_{1 \mathrm{c}}$-lowering potency of saxagliptin and alogliptin at study end versus baseline or the control groups was rather modest in both studies $(0.30 \%$ and $0.36 \%$ ), although one must accept that neither study was designed as a glycemia differential trial. Additionally, the reported pleiotropic cardiovascular effects of DPP-4 inhibitors on lipid-lowering and blood pressure-lowering are quite modest. ${ }^{51}$ It appears from this work that decreasing glucose by a modest amount is highly unlikely to lead to a reduction in cardiovascular risk, at least in the short period over which the trials are conducted. One might also conclude that in order to significantly decrease cardiovascular events in diabetic patients, cholesterol and blood pressure reduction together with smoking cessation are of paramount importance. ${ }^{50}$

Perhaps the most notable finding was the observation of more patients on saxagliptin group than those on placebo being hospitalized for heart failure $(3.5 \%$ versus $2.8 \%$; hazard ratio [HR] $1.27 ; 95 \% \mathrm{CI} 1.07-1.51 ; P=0.007)$. As expected, the risk of hospitalization for heart failure was closely related to N-terminal pro-brain natriuretic peptide levels at baseline in both the saxagliptin and control arms. In patients with the highest quartile of $\mathrm{N}$-terminal pro-brain natriuretic peptide levels at baseline (333-46,627 pg/mL), the risk for heart failure hospitalization was $10.9 \%$ in the saxagliptin group and $8.9 \%$ in the placebo arm (HR 1.31; 95\% CI 1.0-1.6; $P=0.021$ ). The risk for heart failure hospitalization associated with the use of saxagliptin was highest in the first 6 months (HR 1.80; 95\% CI 1.29-2.54; $P<0.001$ ) and declined thereafter (HR 1.48 after one year and 1.28 after 2 years).$^{48}$ As expected, prior heart failure was the strongest predictor of hospitalization for during the study (HR 4.17; 95\% CI 3.48-4.99; P<0.001), followed by impaired kidney function (estimated glomerular filtration rate $<50 \mathrm{~mL}$ per minute, HR 2.39, 95\% CI 1.98-2.88, $P<0.001$; and albumin/creatinine ratio increased $>30 \mathrm{mg} / \mathrm{g}, \mathrm{HR} 2.18$, 95\% CI 1.81-2.63, $P<0.001)$. Other variables such as older age $(>75$ years) or previous myocardial infarction were less predictive. $^{48}$

The overall risk of hospitalization for heart failure in the SAVOR-TIMI study was approximately $2 \%$ yearly, with 289 cases documented in the saxagliptin arm and 228 in the placebo arm. A similar trend was observed in EXAMINE, with 106 subjects in the alogliptin arm and 89 subjects in the placebo arm being hospitalized for heart failure.

Meta-analysis combining data from both studies would suggest an increased risk of hospitalization for heart failure with the use of DPP-4 inhibitors, 395 cases of heart failure with DPP-4 inhibitors versus 317 with placebo (HR 1.24; 95\% CI 1.07-1.44). ${ }^{50}$ It might be somewhat surprising that the increase in risk of hospitalization for heart failure associated with alogliptin was less clear-cut in spite of prior heart failure being almost doubled (28\% versus $14.8 \%$ ), and 
the more frequent medical controls with treatment adaptations in EXAMINE versus SAVOR-TIMI. The great use of $\beta$-blocking agents and the more frequent medical controls with treatment adaptations in EXAMINE might be one of the potential explanations..$^{50}$

If DDP-4 has a genuine adverse effect of DPP-4 on heart failure (whether it is a new development or, as appears most likely currently, may be worsening in those with existing heart failure), the mechanisms are unknown. Recently, a large number of biologically active proteins with putative truncation sites for DPP-4 have been identified, raising many as yet unanswered questions regarding how this ubiquitous enzyme might regulate many different hematopoietic and other cell functions through its effects on different cytokines, chemokines, and other proteins. ${ }^{52}$ It seems probable that a large number of biologically active proteins with putative truncation sites for DPP-4 might contribute to the lack of a beneficial effect of DPP-4 inhibitors on cardiovascular risk despite the fact that GLP-1 is cardioprotective.

\section{Conclusion}

In conclusion, we have reviewed the effects of saxagliptin on fasting and postprandial glycemic control in Japanese patients with T2DM. In view of the effectiveness of incretin-based drugs for Asian Japanese patients with T2DM, saxagliptin is applicable for various pathological conditions (such as obese or lean, with or without heart failure) and is considered to be clinically significant as a new therapeutic option for Japanese patients with T2DM. Saxagliptin also has less concern for hypoglycemia and weight gain which often become problematic in routine care. Further studies involving a larger number of subjects are required, anticipating future progress in the field of diabetes care.

\section{Disclosure}

The authors report no conflicts of interest in this work.

\section{References}

1. International Diabetes Association. The global burden, diabetes and impaired glucose tolerance. Available from: https://www.idf.org/sites/ default/files/The_Global_Burden.pdf. Accessed June 9, 2014.

2. International Diabetes Association. The global burden, mortality. IDF Diabetes Atlas. 6th ed. Available from: http://www.idf.org/diabetesatlas/ global-burden. Accessed June 9, 2014.

3. Holz GG 4th, Kühtreiber WM, Habener JF. Pancreatic beta-cells are rendered glucose-competent by the insulinotropic hormone glucagon-like peptide-1 (7-37). Nature. 1993;361(6410):362-365.

4. Freeman JS. The pathophysiologic role of incretins. J Am Osteopath Assoc. 2007;107 Suppl:S6-S9.

5. Nauck MA, Baller B, Meier JJ. Gastric inhibitory polypeptide and glucagon-like peptide-1 in the pathogenesis of type 2 diabetes. Diabetes. 2004;53 Suppl 3:S190-S196.
6. Ahrén B, Foley JE. The islet enhancer vildagliptin: mechanisms of improved glucose metabolism. Int J Clin Pract Suppl. 2008;159: 8-14.

7. Banerjee M, Younis N, Soran H. Vildagliptin in clinical practice: a review of literature. Expert Opin Pharmacother. 2009;10(16):2745-2757.

8. Palalau AI, Tahrani AA, Piya MK, Barnett AH. DPP-4 inhibitors in clinical practice. Postgrad Med. 2009;121(6):70-100.

9. Namba M, Katsuno T, Kusunoki Y, Matsuo T, Miuchi M, Miyagawa J. New strategy for the treatment of type 2 diabetes mellitus with incretinbased therapy. Clin Exp Nephrol. 2013;17(1):10-15.

10. Konya H, Tsunoda T, Kamitani M, et al. Add-on effect of sitagliptin in an obese type 2 diabetic patient with glimepiride and metformin on blood glucose control and incretin response. J Diabetes Invest. 2012; 3 Suppl 1:S206.

11. Katsuno T, Ikeda H, Ida K, Miyagawa J, Namba M. Add-on therapy with the DPP-4 inhibitor sitagliptin improves glycemic control in insulin-treated Japanese patients with type 2 diabetes mellitus. Endocr J. 2013;60(6):733-742.

12. Kusunoki Y, Katsuno T, Myojin M, et al. Effect of additional administration of acarbose on blood glucose fluctuations and postprandial hyperglycemia in patients with type 2 diabetes mellitus under treatment with alogliptin. Endocr J. 2013;60(4):431-439.

13. Thornberry NA, Gallwitz B. Mechanism of action of inhibitors of dipeptidyl-peptidase-4 (DPP-4). Best Pract Res Clin Endocrinol Metab. 2009;23(4):479-486.

14. Onglyza ${ }^{\circledR}$ (saxagliptin). Full prescribing information. Princeton, NJ, USA: Wilmington, DE. Bristol-Myers Sqibb/AstraZeneca Pharmaceuticals LP; 2009.

15. Rosenstock J, Aguilar-Salinas C, Klein E, Nepal S, List J, Chen R. Effect of saxagliptin monotherapy in treatment-naive patients with type 2 diabetes. Curr Med Res Opin. 2009;25(10):2401-2411.

16. DeFronzo R, Hissa MN, Garber AJ, et al. Once-daily saxagliptin added to metformin provides sustained glycemic control and is well tolerated over 102 weeks in patients with type 2 diabetes. Diabetes. 2009; 58 Suppl 1:547P.

17. Chacra AR, Tan GH, Ravichandran S, List J, Chen R; CV181-040 Investigators. Safety and efficacy of saxagliptin in combination with submaximal sulphonylurea versus up-titrated sulphonylurea over 76 weeks. Diab Vasc Dis Res. 2011;8(2):150-159.

18. Hollander PL, Li J, Frederich R, Allen E, Chen R; CV181-013 Investigators. Safety and efficacy of saxagliptin added to thiazolidinedione over 76 weeks in patients with type 2 diabetes mellitus. Diab Vasc Dis Res. 2011;8(2):125-135.

19. Pfützner A, Paz-Pacheco E, Allen E, Frederich B, Chen R; for the CV181039 Investigators. Initial combination therapy with saxagliptin and metformin provides sustained glycaemic control and is well tolerated for up to 76 weeks. Diabetes Obes Metab. 2011;13(6): $567-576$.

20. Frederich R, McNeill R, Berglind N, Fleming D, Chen R. The efficacy and safety of the dipeptidyl peptidase-4 inhibitor saxagliptin in treatment-naïve patients with type 2 diabetes mellitus: a randomized controlled trial. Diabetol Metab Syndr. 2012;4(1):36.

21. Poolsup N, Suksomboon N, Setwiwattanakul W. Efficacy of various antidiabetic agents as add-on treatments to metformin in type 2 diabetes mellitus: systematic review and meta-analysis. ISRN Endocrinol. 2012;2012:798146.

22. Gross JL, Kramer CK, Leitão CB, et al. Effect of antihyperglycemic agents added to metformin and a sulfonylurea on glycemic control and weight gain in type 2 diabetes: a network meta-analysis. Ann Intern Med. 2011;154(10):672-679.

23. Phung OJ, Sobieraj DM, Engel SS, Rajpathak SN. Early combination therapy for the treatment of type 2 diabetes mellitus: systematic review and meta-analysis. Diabetes Obes Metab. 2014;16(5): 410-417.

24. Kahn SE. The relative contributions of insulin resistance and beta-cell dysfunction to the pathophysiology of type 2 diabetes. Diabetologia. 2003;46(1):3-19. 
25. Matsumoto K, Miyake S, Yano M, et al. Glucose tolerance, insulin secretion, and insulin sensitivity in nonobese and obese Japanese subjects. Diabetes Care. 1997;20(10):1562-1568.

26. Pratley RE, Weyer C. The role of impaired early insulin secretion in the pathogenesis of type II diabetes mellitus. Diabetologia. 2002;44(8): 929-945.

27. Fukushima M, Suzuki H, Seino Y. Insulin secretion capacity in the development from glucose tolerance to type 2 diabetes. Diabetes Res Clin Pract. 2004;66 Suppl 1:S37-S43.

28. Fukuda-Akita E, Okita K, Okauchi Y, et al. Impaired early insulin secretion in Japanese type 2 diabetes with metabolic syndrome. Diabetes Res Clin Pract. 2008;79(3):482-489.

29. Mandavilli A, Cyranoski D. News feature: Asia's big problem. Nat Med. 2004;10(4):325-327.

30. Iwahashi H, Okauchi Y, Ryo M, et al. Insulin-secretion capacity in normal glucose tolerance, impaired glucose tolerance, and diabetes in obese and non-obese Japanese patients. J Diabetes Invest. 2012;3(3): 271-275.

31. Iwao T, Sakai K, Ando E. Relative contribution of insulin secretion and sensitivity at different stages of glucose tolerance: non-obese versus obese Japanese subjects. Intern Med. 2014;53(5):383-390.

32. Seino Y, Fukushima M, Yabe D. GIP and GLP-1, the two incretin hormones: similarities and differences. J Diabetes Invest. 2010;1(1-2): 9-23.

33. Chan CN, Malik V, Jia W, et al. Diabetes in Asia epidemiology, risk factors, and pathophysiology. JAMA. 2009;301(20):2129-2140.

34. Park H, Park C, Kim Y, Rascati KL. Efficacy and safety of dipeptidyl peptidase-4 inhibitors in type 2 diabetes: meta-analysis. Ann Pharmacother. 2012;46(11):1453-1469.

35. Kim YG, Hahn S, Oh TJ, Kwak SH, Park KS, Cho YM. Differences in the glucose-lowering efficacy of dipeptidyl peptidase-4 inhibitors between Asians and non-Asians: a systematic review and meta-analysis. Diabetologia. 2013;56(4):696-708.

36. Aso Y, Ozeki N, Terasawa T, et al. Serum level of soluble CD26/ dipeptidyl peptidase-4 (DPP-4) predicts the response to sitagliptin, a DPP-4 inhibitor, in patients with type 2 diabetes controlled inadequately by metformin and/or sulfonylurea. Transl Res. 2012;159(1):25-31.

37. Horikawa C, Yoshimura Y, Kamada C, et al. Dietary intake in Japanese patients with type 2 diabetes: analysis from Japan Diabetes Complications Study. J Diabetes Investig. 2014;5(2):176-187.

38. Wong MC, Wang HH, Kwan MW, et al. Comparative effectiveness of dipeptidyl peptidase-4 (DPP-4) inhibitors and human glucagon-like peptide-1 (GLP-1) analogue as add-on therapies to sulphonylurea among diabetes patients in the Asia-Pacific region: a systematic review. PLoS One. 2014;9(3):e90963.

39. Kawamori R. Diabetes trends in Japan. Diabetes Metab Res Rev. 2002; 18 Suppl 3:S9-S13.
40. Kobayashi M, Yamazaki K, Hirao K, et al. The status of diabetes control and antidiabetic drug therapy in Japan - a cross-sectional survey of 17,000 patients with diabetes mellitus (JDDM 1). Diabetes Res Clin Pract. 2006;73(2):198-204.

41. Kozawa J, Kitamura T, Nishizawa H, et al. Dipeptidyl peptidase-4 inhibitors are effective in Japanese type 2 diabetic patients with sustained endogenous insulin-secreting capacity, a higher body mass index and insulin resistance. J Diabetes Invest. 2013;4(2):190-194.

42. Kadowaki T. Efficacy and safety of a novel DPP-4 inhibitor saxagliptin in patients with type 2 diabetes mellitus - the results of clinical trials in Japan. Jap Pharmacol Ther. 2013;41(8):803-815.

43. Onglyza ${ }^{\circledR}$ (saxagliptin). A Phase II multiple dose study in Japanese patients. Summary of Product Characteristics. Tokyo, Japan: Kyowa Hakko Kirin Co, Ltd; 2009. Available from http://www.kksmile.com/ druginfo/interv/ong_in.pdf. Accessed June 30, 2014.

44. Onglyza ${ }^{\circledR}$ (saxagliptin). A Phase III long-term monotherapy trial in Japanese patients. Summary of Product Characteristics. Tokyo, Japan: Kyowa Hakko Kirin Co, Ltd; 2011. Available from http://www.kksmile. com/druginfo/interv/ong_in.pdf. Accessed June 30, 2014.

45. Onglyza ${ }^{\circledR}$ (saxagliptin). A phase III long-term combination therapy trial in Japanese patients. Summary of Product Characteristics. Tokyo, Japan: Kyowa Hakko Kirin Co, Ltd; 2012. Available from http://www. kksmile.com/druginfo/interv/ong_in.pdf. Accessed June 30, 2014.

46. Frederich R, Alexander JH, Fiedorek FT, et al. A systematic assessment of cardiovascular outcomes in the saxagliptin drug development program for type 2 diabetes. Postgrad Med. 2010;122(3):16-27.

47. Mosenzon O, Raz I, Scirica BM, et al. Baseline characteristics of the patient population in the Saxagliptin Assessment of Vascular Outcomes Recorded in patients with diabetes mellitus (SAVOR)-TIMI 53 trial. Diabetes Metab Res Rev. 2013;29(5):417-426.

48. Scirica BM, Bhatt DL, Braunwald E, et al. Saxagliptin and cardiovascular outcomes in patients with type 2 diabetes mellitus. N Engl J Med. 2013;369(14):1317-1326.

49. White WB, Cannon CP, Heller SR, et al. Alogliptin after acute coronary syndrome in patients with type 2 diabetes. N Engl J Med. 2013;369(14): 1327-1335.

50. Schernthaner G, Sattar N. Lessons from SAVOR and EXAMINE: some important answers, but many open questions. J Diabetes Complications. February 26, 2014. [Epub ahead of print.]

51. Scheen AJ. Cardiovascular effects of dipeptidyl peptidase-4 inhibitors: from risk factors to clinical outcomes. Postgrad Med. 2013;125(3): $7-20$.

52. Ou X, O’Leary HA, Broxmeyer HE. Implications of DPP4 modification of proteins that regulate stem/progenitor and more mature cell types. Blood. 2013;122(2):161-169.
Therapeutics and Clinical Risk Management

\section{Publish your work in this journal}

Therapeutics and Clinical Risk Management is an international, peerreviewed journal of clinical therapeutics and risk management, focusing on concise rapid reporting of clinical studies in all therapeutic areas, outcomes, safety, and programs for the effective, safe, and sustained use of medicines. This journal is indexed on PubMed Central, CAS,
Dovepress

EMBase, Scopus and the Elsevier Bibliographic databases. The manuscript management system is completely online and includes a very quick and fair peer-review system, which is all easy to use. Visit http://www.dovepress.com/testimonials.php to read real quotes from published authors. 